\title{
Anthropometric Obesity Indices, Body Fat Percentage, and Grip Strength in Young Adults with different Physical Activity Levels
}

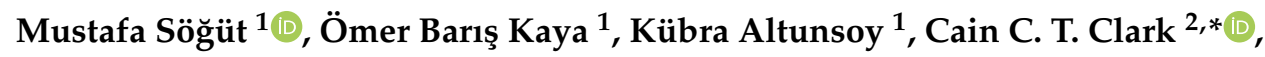 \\ Filipe Manuel Clemente ${ }^{3,4}$ (1) and Ali Ahmet Doğan ${ }^{1}$ \\ 1 Faculty of Sport Sciences, Kırıkkale University, Kırıkkale 71450 Turkey \\ 2 Centre for Sport, Exercise and Life Sciences, Coventry University, Coventry CV1 5FB, UK \\ 3 Polytechnic Institute of Viana do Castelo, School of Sport and Leisure, 4960-320 Melgaço, Portugal \\ 4 Instituto de Telecomunicações, 6200-001 Delegação da Covilhã, Portugal \\ * Correspondence: cain.clark@coventry.ac.uk
}

Received: 5 July 2019; Accepted: 30 July 2019; Published: 31 July 2019

\begin{abstract}
The purposes of this study were to determine whether moderately physically active (MPA) and highly physically active (HPA) male ( $n=96$, age $=22.5 \pm 1.7$ years) and female $(n=85$, age $=21.3 \pm 1.6$ years) young adults differed in their anthropometric obesity indices (AOIs), body fat percentage $(\mathrm{BF} \%)$, and muscular strength, and also to examine the associations between physical activity level (PAL) and the abovementioned variables. Participants were measured for body height and weight, $\mathrm{BF} \%$, waist and hip circumferences, and maximal isometric grip strength. According to their PAL, estimated by the short version of the International Physical Activity Questionnaire, they were assigned to MPA and HPA subgroups. Regardless of gender, results indicated that participants in the MPA groups had significantly higher values of body weight, waist and hip circumference, $\mathrm{BF} \%$, and BMI than participants in the HPA groups. No significant differences were found between physical activity groups in terms of grip strength. The AOIs and BF\% were found to be significantly and negatively correlated with the PAL in both genders. In conclusion, the findings of the study suggest that high habitual physical activity is associated with lower adiposity markers. However, the differences in the hand grip strength of the contrasting activity groups were negligible.
\end{abstract}

Keywords: obesity indices; body composition; grip strength; physical activity

\section{Introduction}

The consequences of physical inactivity, including a diverse range of chronic and non-communicable diseases is well-documented, such as coronary heart disease [1], breast and colon cancers [2,3], osteoporosis [4], noninsulin-dependent diabetes [5], excess adiposity [6], depression [7], and all-cause mortality [8]. Nevertheless, sedentary lifestyle behaviors are still common worldwide [9], and it presents a major global public health concern.

Accumulating evidence suggests that habitual physical activity has a positive influence on various health outcomes [10-12]. The findings of large, recent cohort studies have indicated that physical activity level (PAL) is inversely associated with body fat percentage (BF\%), body mass index (BMI), and/or other adiposity indicators [13-16]. Notwithstanding, inconsistent results have been observed in certain age groups with regard to the relationship between physical activity and muscular strength [17-20].

Muscular strength is a determinant of physical quality that ensures a lower cardiovascular risk factor [21], a healthy mineral bone density, and high levels of lean mass [22], independently of other 
fitness variables or sociodemographic measures. Despite there being many ways to assess muscular strength, one of the most common tests carried out in adults is grip strength, which is an important clinical and prognostic value [23]. Usually, strong and positive correlations have been found between hand grip strength and muscle mass [24]. On the other hand, low hand grip strength is associated with increased risk of functional limitations and disability in one's later years, as well as a general cause of mortality [25]. In spite of such evidence, there is a lack of studies testing the relationship between PALs and strength, and this should be considered to understand the mechanism that explains good maintenance of strength.

Although young adulthood is a critical developmental period characterized by important changes in health status, such as unhealthy weight gain $[26,27]$ and physical inactivity [28], the majority of the relevant examinations have been conducted with children and older adults. Thus, current literature provides limited evidence on the disparities in adiposity and muscular strength in university students with different PALs. Therefore, the purposes of the present study were to examine whether moderately physically active (MPA) and highly physically active (HPA) male and female young adults differed in their anthropometric obesity indices (AOIs), $\mathrm{BF} \%$, and muscular strength, and to analyze the relations between PAL and the aforementioned variables.

\section{Materials and Methods}

\subsection{Participants}

A cohort of male ( $n=96$, age $=22.5 \pm 1.7$ years $)$ and female $(n=85$, age $=21.3 \pm 1.6$ years $)$ university students from a state university located in central Anatolia (Turkey) were recruited to take part in the study. They were initially briefed of the measurement procedures and the aims of the study, and then requested to sign informed consent forms. Ethical approval was obtained from the Non-interventional Researches Ethics Board of Kırıkkale University (approval number/identification code of the study is 2019.06.25).

\subsection{Anthropometric Measurements}

Anthropometric assessments were performed in accordance with standardized procedures [29]. Body height was measured with a portable stadiometer (Seca 213, Hamburg, Germany) to the nearest $0.1 \mathrm{~cm}$. Body mass $(0.1 \mathrm{~kg}$ ) and BF\% were evaluated by a bioelectrical impedance analyzer (Tanita, BC-418, Japan). Waist and hip circumferences were measured with a flexible steel tape to the nearest centimeter at the smallest circumference between the ribs and the iliac crest and at the level of maximum protuberance of the buttocks, respectively. BMI was calculated by dividing the body weight $(\mathrm{kg})$ by the body height squared (m).

\subsection{Grip Strength}

A digital hand dynamometer (T.K.K.5401 Grip-D, Takei, Japan) was used to assess maximal isometric grip strength. Participants were asked to stay in a standing position and keep one arm straight and parallel to the body. They were requested to hold the dynamometer with their dominant hand and squeeze the handle as hard as possible for three seconds. The highest value acquired from the three trials was used for the analysis.

\subsection{Physical Activity}

The PAL of the participants was estimated via the short form of the International Physical Activity Questionnaire (IPAQ) [30,31]. The IPAQ requires respondents to recall the frequency, duration, and intensity of physical activity they engaged in during the last seven days. Each type of activity (moderateand vigorous-intensity walking) was then converted to metabolic equivalent (MET) minutes, enabling the determination of total weekly physical activity. Based on their weekly MET minutes, they were divided into two groups-MPA ( $\geq 600-3000 \mathrm{MET}$ min/week) and HPA ( $\geq 3000$ MET min/week) [30,31]. 


\subsection{Statistical Analysis}

Data were analyzed using SPSS for Windows. Descriptive statistics (mean \pm SD) were calculated for all variables. An independent sample t-test was used to ascertain differences between PAL groups. Effect sizes (ES) were quantified to determine the magnitude of differences. Based on the Cohen's d values, ES were considered as: $<0.20$ (trivial), 0.20 to 0.59 (small), 0.60 to 1.19 (moderate), 1.20 to 1.99 (large), 2.0 to 3.9 (very large), and $>4.0$ (extremely large) [32]. A Pearson correlation coefficient was conducted to examine the associations between PAL and other variables. Correlations were categorized as $0.0-0.1$ (trivial), $0.1-0.3$ (small), 0.3-0.5 (moderate), 0.5-0.7 (large), 0.7-0.9 (very large), and 0.9-1.0 (near perfect) [32].

\section{Results}

Descriptive statistics (mean \pm SD), t-test results, and effect sizes for male and female participants are presented in Tables 1 and 2. Results highlighted that participants in the HPA groups had significantly lower values in $\mathrm{BF} \%$, body mass, waist and hip circumference, and BMI than the participants in the MPA groups in both genders. There were no significant differences in age, body height, and grip strength results between groups.

Table 1. Descriptive statistics, t-test results, and effect size values for male participants.

\begin{tabular}{cccccc}
\hline $\begin{array}{c}\text { Physical Activity } \\
\text { Groups }\end{array}$ & MPA $(\boldsymbol{n}=\mathbf{4 5})$ & HPA $(\boldsymbol{n}=\mathbf{5 1})$ & $\boldsymbol{t}$ & $\boldsymbol{p}$ & $\boldsymbol{d}$ \\
\hline Age (years) & $22.8(1.8)$ & $22.2(1.6)$ & 1.861 & 0.066 & 0.38 \\
Activity (MET m/w) & $1922.1(799.2)$ & $4883.1(1203.3)$ & -14.001 & 0.001 & -2.89 \\
Height (cm) & $175.2(6.3)$ & $175.1(6.8)$ & 0.082 & 0.935 & 0.02 \\
Weight (kg) & $71.9(8.1)$ & $68.4(7.5)$ & 2.245 & 0.027 & 0.46 \\
Waist (cm) & $80.1(5.7)$ & $77.1(4.9)$ & 2.707 & 0.008 & 0.55 \\
Hip (cm) & $96.2(4.8)$ & $93.7(5.4)$ & 2.347 & 0.021 & 0.46 \\
BMI (kg/m $\left.{ }^{2}\right)$ & $23.50(2.7)$ & $22.34(2.2)$ & 2.285 & 0.025 & 0.46 \\
Body fat $(\%)$ & $13.5(5.8)$ & $10.5(3.8)$ & 3.275 & 0.001 & 0.67 \\
Grip strength $(\mathrm{kg})$ & $47.5(7.0)$ & $47.9(6.8)$ & -0.291 & 0.772 & -0.06 \\
\hline
\end{tabular}

Table 2. Descriptive statistics, t-test results, and effect size values for female participants.

\begin{tabular}{cccccc}
\hline $\begin{array}{c}\text { Physical Activity } \\
\text { Groups }\end{array}$ & MPA $(n=37)$ & HPA $(n=48)$ & $t$ & $p$ & $\boldsymbol{d}$ \\
\hline Age (years) & $21.2(1.7)$ & $21.3(1.6)$ & -0.324 & 0.747 & -0.07 \\
Activity (MET m/w) & $1665.3(777.5)$ & $4863.2(821.2)$ & -18.214 & 0.001 & -3.98 \\
Height (cm) & $162.1(5.6)$ & $161.2(6.6)$ & 0.705 & 0.483 & 0.15 \\
Weight (kg) & $60.8(11.9)$ & $54.8(8.7)$ & 2.646 & 0.010 & 0.58 \\
Waist (cm) & $69.9(8.1)$ & $66.7(5.2)$ & 2.184 & 0.032 & 0.48 \\
Hip (cm) & $96.8(7.8)$ & $93.3(6.3)$ & 2.257 & 0.027 & 0.49 \\
BMI (kg/m $\left.{ }^{2}\right)$ & $23.05(4.2)$ & $21.03(2.7)$ & 2.703 & 0.008 & 0.59 \\
Body fat $(\%)$ & $27.6(8.1)$ & $22.4(6.5)$ & 3.301 & 0.001 & 0.72 \\
Grip strength $(\mathrm{kg})$ & $27.2(4.4)$ & $27.3(3.8)$ & -0.182 & 0.856 & -0.04 \\
\hline
\end{tabular}

Table 3 presents the correlation coefficients between PAL and other variables for each gender, separately. Results indicated that the PAL, regardless of gender, was found to be significantly and negatively correlated with all $\mathrm{AOIs}$ and $\mathrm{BF} \%$. On the other hand, no significant associations were found between PAL and grip strength values in both male and female participants. 
Table 3. Correlation results between physical activity level (PAL) and other variables by gender.

\begin{tabular}{ccccc}
\hline \multirow{2}{*}{ Variables } & \multicolumn{2}{c}{ Male } & \multicolumn{2}{c}{ Female } \\
\cline { 2 - 5 } & $\boldsymbol{r}$ & $\boldsymbol{p}$ & $\boldsymbol{r}$ & $\boldsymbol{p}$ \\
\hline Height & 0.012 & 0.905 & -0.016 & 0.886 \\
Weight & -0.211 & 0.039 & -0.304 & 0.005 \\
Waist & -0.373 & 0.001 & -0.246 & 0.023 \\
Hip & -0.284 & 0.005 & -0.296 & 0.006 \\
BMI & -0.227 & 0.026 & -0.342 & 0.001 \\
BF\% & -0.432 & 0.001 & -0.398 & 0.001 \\
Grip strength & -0.033 & 0.746 & 0.100 & 0.364 \\
\hline
\end{tabular}

\section{Discussion}

The aim of the present study was to investigate the possible differences in various adiposity parameters and muscular strength in a group of young male and female adults with distinct physical activity profiles. The results of the study indicated that the participants in the HPA group had significantly lower values in all AOIs and $\mathrm{BF} \%$ than their MPA counterparts in both genders. Furthermore, regardless of gender, PAL was found to be significantly and negatively correlated with AOIs and $\mathrm{BF} \%$. The results, with regard to reported correlation coefficients, are in line with the findings of previous longitudinal [33-35] and cross-sectional [36,37] examinations. Concordant with our findings, results of some recent work noted similar observations, that individuals who engaged in greater physical activity were found to have preferential indices of adiposity [13,14].

The results demonstrated that there were no significant differences in grip strength results between activity groups. This observation is in accord with the findings of previous studies conducted with children [38], young adults [39], and older adults [40]. Furthermore, no significant associations were obtained between PAL and grip strength values in both genders. This might conceivably be attributed to comparable body sizes, where trivial and small magnitudes of differences were found between groups for body height and weight, respectively. Furthermore, the participants were grouped by the IPAQ, which does not specifically assess participation in strengthening activities, so may not be sufficiently sensitive. In addition, other possible anthropometric correlates of hand grip strength that were not measured in this study, such as hand size and forearm circumference [41], total arm length and upper arm circumference [42], and hand circumference [43] might contribute to this insignificance, and therefore warrants further examination.

With regard to practical implications, it is conceivable that high PALs and good levels of strength may help to maintain health levels across adulthood. Different studies have suggested that upper and lower body muscular strength are important factors that contribute to a lower risk of mortality in the adult population, regardless of age [44,45]. Although no differences were found between PALs in strength, it is important to highlight that strength is an independent physical quality and should be worked out concurrently with other fitness components (e.g., cardiorespiratory fitness). Thus, a healthy lifestyle should include both cardiorespiratory and muscular strength training/stimuli [46].

\section{Conclusions}

The findings of the present study revealed that higher levels of habitual physical activity is associated with lower adiposity markers in young adults. Nevertheless, differences in hand grip strength of the contrasting activity groups were negligible. It should also be acknowledged that the current study has several limitations. Firstly, the subjective assessment may cause incorrect estimation of physical activity; however, use of the well-validated IPAQ ameliorates some concern. Secondly, in spite of its important advantages (i.e., being relatively inexpensive, portable, and quick), rather than BIA, criterion methods such as underwater weighing or dual-energy $\mathrm{x}$-ray absorptiometry might be used to determine body fat, but nevertheless present significant time and cost restrictions. Nevertheless, 
it is recommended that future studies expand this observation through using a larger sample and more complex reference methods to measure physical activity levels and body composition.

Author Contributions: Conceptualization, M.S. and O.B.K.; Data curation, M.S. and O.B.K.; Formal analysis, M.S.; Investigation, K.A. and F.M.C.; Software, M.S.; Supervision, C.C.T.C. and A.A.D.; Writing-original draft, M.S., O.B.K., K.A., C.C.T.C. and F.M.C.; Writing-review and editing, C.C.T.C. and A.A.D.

Funding: This research received no external funding.

Conflicts of Interest: The authors declare no conflict of interest.

\section{References}

1. Sattelmair, J.; Pertman, J.; Ding, E.L.; Kohl, H.W., III; Haskell, W.; Lee, I.M. Dose response between physical activity and risk of coronary heart disease: A meta-analysis. Circulation 2011, 124, 789-795. [CrossRef] [PubMed]

2. Friedenreich, C.M. Physical activity and breast cancer: Review of the epidemiologic evidence and biologic mechanisms. Recent Results Cancer Res. 2011, 188, 125-139. [PubMed]

3. Wolin, K.Y.; Yan, Y.; Colditz, G.A.; Lee, I.M. Physical activity and colon cancer prevention: A meta-analysis. Br. J. Cancer 2009, 100, 611. [CrossRef] [PubMed]

4. Lane, N.E. Epidemiology, etiology, and diagnosis of osteoporosis. Am. J. Obstet. Gynecol. 2006, 19 , S3-S11. [CrossRef] [PubMed]

5. Jeon, C.Y.; Lokken, R.P.; Hu, F.B.; Van Dam, R.M. Physical activity of moderate intensity and risk of type 2 diabetes: A systematic review. Diabetes Care 2007, 30, 744-752. [PubMed]

6. Pietiläinen, K.H.; Kaprio, J.; Borg, P.; Plasqui, G.; Yki-Järvinen, H.; Kujala, U.M.; Rose, R.J.; Westerterp, K.R.; Rissanen, A. Physical inactivity and obesity: A vicious circle. Obesity 2008, 16, 409-414. [CrossRef] [PubMed]

7. Weyerer, S. Physical Inactivity and Depression in the Community. Int. J. Sports Med. 1992, 13, $492-496$. [CrossRef]

8. Lollgen, H.; Bockenhoff, A.; Knapp, G. Physical activity and all-cause mortality: An updated metaanalysis with different intensity categories. Int. J. Sports Med. 2009, 30, 213-224. [CrossRef]

9. Hallal, P.C.; Andersen, L.B.; Bull, F.C.; Guthold, R.; Haskell, W.; Ekelund, U.; Lancet Physical Activity Series Working Group. Global physical activity levels: Surveillance progress, pitfalls, and prospects. Lancet 2012, 380, 247-257. [CrossRef]

10. Blair, S.N.; Cheng, Y.; Holder, J.S. Is physical activity or physical fitness more important in defining health benefits? Med. Sci. Sports Exerc. 2001, 33, 379-399.

11. Reiner, M.; Niermann, C.; Jekauc, D.; Woll, A. Long-term health benefits of physical activity-A systematic review of longitudinal studies. BMC Public Health 2013, 13, 813. [CrossRef]

12. Warburton, D.E.; Nicol, C.W.; Bredin, S.S. Health benefits of physical activity: The evidence. Can. Med. Assoc. J. 2006, 174, 801-809. [CrossRef] [PubMed]

13. Besson, H.; Ekelund, U.; Luan, J.; May, A.M.; Sharp, S.; Travier, N.; Agudo, A.; Slimani, N.; Rinaldi, S.; Jenab, M.; et al. A cross-sectional analysis of physical activity and obesity indicators in European participants of the EPIC-PANACEA study. Int. J. Obes. 2009, 33, 497-506. [CrossRef] [PubMed]

14. Maher, C.A.; Mire, E.; Harrington, D.M.; Staiano, A.E.; Katzmarzyk, P.T. The independent and combined associations of physical activity and sedentary behavior with obesity in adults: NHANES 2003-06. Obesity 2013, 21, 730-737. [CrossRef] [PubMed]

15. Moliner-Urdiales, D.; Ruiz, J.R.; Ortega, F.B.; Rey-Lopez, J.P.; Vicente-Rodríguez, G.; España-Romero, V.; Izquierdo, D.M.; Castillo, M.J.; Sjöström, M.; Moreno, L.A. Association of objectively assessed physical activity with total and central body fat in Spanish adolescents; The HELENA Study. Int. J. Obes. 2009, 33, 1126-1135. [CrossRef]

16. Ruiz, J.R.; Rizzo, N.S.; Hurtig-Wennlöf, A.; Ortega, F.B.; Wàrnberg, J.; Sjöström, M. Relations of total physical activity and intensity to fitness and fatness in children: The European Youth Heart Study. Am. J. Clin. Nutr. 2006, 84, 299-303. [CrossRef] 
17. Bann, D.; Hire, D.; Manini, T.; Cooper, R.; Botoseneanu, A.; McDermott, M.M.; Pahor, M.; Glynn, N.W.; Fielding, R.; King, A.C.; et al. Light intensity physical activity and sedentary behavior in relation to body mass index and grip strength in older adults: Cross-sectional findings from the lifestyle interventions and independence for elders (LIFE) study. PLoS ONE 2015, 10, e0116058.

18. Cooper, A.J.M.; Lamb, M.J.E.; Sharp, S.J.; Simmons, R.K.; Griffin, S.J. Bidirectional association between physical activity and muscular strength in older adults: Results from the UK Biobank study. Int. J. Epidemiol. 2016, 46, 141-148.

19. Martin, H.J.; Syddall, H.E.; Dennison, E.M.; Cooper, C.; Sayer, A.A. Relationship between customary physical activity, muscle strength and physical performance in older men and women: Findings from the Hertfordshire Cohort Study. Age Ageing 2008, 37, 589-593. [CrossRef]

20. Westbury, L.D.; Dodds, R.M.; Syddall, H.E.; Baczynska, A.M.; Shaw, S.C.; Dennison, E.M.; Roberts, H.C.; Sayer, A.A.; Cooper, C.; Patel, H.P. Associations Between Objectively Measured Physical Activity, Body Composition and Sarcopenia: Findings from the Hertfordshire Sarcopenia Study (HSS). Calcif. Tissue Int. 2018, 103, 237-245.

21. Grøntved, A.; Ried-Larsen, M.; Møller, N.C.; Kristensen, P.L.; Froberg, K.; Brage, S.; Andersen, L.B. Muscle strength in youth and cardiovascular risk in young adulthood (the European Youth Heart Study). Br. J. Sports Med. 2015, 49, 90-94. [CrossRef]

22. Guimarães, B.R.; Pimenta, L.D.; Massini, D.A.; Dos Santos, D.; da Cruz Siqueira, L.O.; Simionato, A.R.; dos Santos, L.G.A.; Neiva, C.M.; Filho, D.M.P. Muscle strength and regional lean body mass influence on mineral bone health in young male adults. PLoS ONE 2018, 13, e0191769. [CrossRef]

23. Bohannon, R.W. Muscle strength: Clinical and prognostic value of hand-grip dynamometry. Curr. Opin. Clin. Nutr. Metab. Care 2015, 18, 465-470. [CrossRef]

24. Steffl, M.; Bohannon, R.W.; Houdova, V.; Musalek, M.; Prajerova, K.; Cesak, P.; Petra, M.; Kohlikovaa, E.; Holmerova, I. Association between clinical measures of sarcopenia in a sample of community-dwelling women. Isokinet. Exerc. Sci. 2015, 23, 41-44. [CrossRef]

25. Norman, K.; Stobäus, N.; Gonzalez, M.C.; Schulzke, J.D.; Pirlich, M. Hand grip strength: Outcome predictor and marker of nutritional status. Clin. Nutr. 2011, 30, 135-142. [CrossRef]

26. Gordon-Larsen, P.; Adair, L.S.; Nelson, M.C.; Popkin, B.M. Five-year obesity incidence in the transition period between adolescence and adulthood: The National Longitudinal Study of Adolescent Health. Am. J. Clin. Nutr. 2004, 80, 569-575.

27. Lee, H.; Lee, D.; Guo, G.; Harris, K.M. Trends in body mass index in adolescence and young adulthood in the United States: 1959-2002. J. Adolesc. Health 2011, 49, 601-608.

28. Telama, R.; Yang, X. Decline of physical activity from youth to young adulthood in Finland. Med. Sci. Sports Exerc. 2000, 32, 1617-1622. [CrossRef]

29. Lohman, T.G.; Roche, A.F.; Martorell, R. Anthropometric Standardization Reference Manual; Human Kinetics: Champaign, IL, USA, 1988.

30. Craig, C.L.; Marshall, A.L.; Sjostrom, M.; Bauman, A.E.; Booth, M.L.; Ainsworth, B.E.; Pratt, M.; Ekelund, U.; Yngve, A.; Sallis, J.F.; et al. International physical activity questionnaire: 12-Country reliability and validity. Med. Sci. Sports Exer. 2003, 35, 1381-1395. [CrossRef]

31. IPAQ Research Committee. Guidelines for Data Processing and Analysis of the International Physical Activity Questionnaire-Short and Long Forms. 2005. Available online: http://www.ipaq.ki.se (accessed on 5 May 2019).

32. Hopkins, W.G.; Marshall, S.W.; Batterham, A.M.; Hanin, J. Progressive statistics for studies in sports medicine and exercise science. Med. Sci. Sports Exer. 2009, 41, 3-13. [CrossRef]

33. Bell, A.C.; Ge, K.; Popkin, B.M. Weight gain and its predictors in Chinese adults. Int. J. Obes. 2001, 25, 1079-1086. [CrossRef]

34. Schmitz, K.H.; Jacobs, D.R., Jr.; Leon, A.S.; Schreiner, P.J.; Sternfeld, B. Physical activity and body weight: Associations over ten years in the CARDIA study. Int. J. Obes. 2000, 24, 1475-1487. [CrossRef]

35. Wagner, A.; Simon, C.; Ducimetiere, P.; Montaye, M.; Bongard, V.; Yarnell, J.; Bingham, A.; Hedelin, G.; Amouyel, P.; FerrieÁres, J.; et al. Leisure-time physical activity and regular walking or cycling to work are associated with adiposity and $5 \mathrm{y}$ weight gain in middle-aged men: The PRIME Study. Int. J. Obes. 2001, 25, 940-948. [CrossRef] 
36. Bowen, L.; Taylor, A.E.; Sullivan, R.; Ebrahim, S.; Kinra, S.; Krishna, K.R.; Krishna, K.V.R.; Kulkarni, B.; Ben-Shlomo, Y.; Ekelund, U.; et al. Associations between diet, physical activity and body fat distribution: A cross sectional study in an Indian population. BMC Public Health 2015, 15, 281. [CrossRef]

37. Zanovec, M.; Lakkakula, A.P.; Johnson, L.G.; Turri, G. Physical activity is associated with percent body fat and body composition but not body mass index in white and black college students. Int. J. Exerc. Sci. 2009, 2, 175-185.

38. Cho, M.; Kim, J.Y. Changes in physical fitness and body composition according to the physical activities of Korean adolescents. J. Exerc. Rehabil. 2017, 13, 568-572.

39. Mikaelsson, K.; Eliasson, K.; Lysholm, J.; Nyberg, L.; Michaelson, P. Physical capacity in physically active and non-active adolescents. J. Public Health 2011, 19, 131-138. [CrossRef]

40. Morie, M.; Reid, K.F.; Miciek, R.; Lajevardi, N.; Choong, K.; Krasnoff, J.B.; Storer, T.W.; Fielding, R.A.; Bhasin, S.; Lebrasseur, N.K. Habitual Physical Activity Levels are Associated with Performance in Measures of Physical Function and Mobility in Older Men. J. Am. Geriatr. Soc. 2010, 58, 1727-1733. [CrossRef]

41. Günther, C.M.; Bürger, A.; Rickert, M.; Crispin, A.; Schulz, C.U. Grip strength in healthy caucasian adults: Reference values. J. Hand Surg. 2008, 33, 558-565. [CrossRef]

42. Koley, S.; Singh, A.P. An association of dominant hand grip strength with some anthropometric variables in Indian collegiate population. Anthropol. Anz. 2009, 67, 21-28. [CrossRef]

43. Li, K.; Hewson, D.J.; Duchêne, J.; Hogrel, J.Y. Predicting maximal grip strength using hand circumference. Man. Ther. 2010, 15, 579-585. [CrossRef]

44. García-Hermoso, A.; Cavero-Redondo, I.; Ramírez-Vélez, R.; Ruiz, J.R.; Ortega, F.B.; Lee, D.C.; Martínez-Vizcaíno, V. Muscular strength as a predictor of all-cause mortality in an apparently healthy population: A systematic review and meta-analysis of data from approximately 2 million men and women. Arch. Phys. Med. Rehabil. 2018, 99, 2100-2113. [CrossRef]

45. Volaklis, K.A.; Halle, M.; Meisinger, C. Muscular strength as a strong predictor of mortality: A narrative review. Eur. J. Intern. Med. 2015, 26, 303-310. [CrossRef]

46. Schumann, M.; Yli-Peltola, K.; Abbiss, C.R.; Häkkinen, K. Cardiorespiratory adaptations during concurrent aerobic and strength training in men and women. PLoS ONE 2015, 10, e0139279. [CrossRef]

(C) 2019 by the authors. Licensee MDPI, Basel, Switzerland. This article is an open access article distributed under the terms and conditions of the Creative Commons Attribution (CC BY) license (http://creativecommons.org/licenses/by/4.0/). 